SHORT REPORT

\title{
Perceived risk from occupational stress: a survey of 15 European countries
}

\section{K Daniels}

\begin{abstract}
Aims: To examine the ranking of workers in 15 European countries with respect to the extent that work is perceived to influence occupational stress.

Methods: International interviewer administered cross-sectional survey. Control variables included demographics, perceived job conditions, and job satisfaction. A sample of working adults $(n=11054)$ from 15 European countries were studied.

Results: In three statistical models, the British sample ranked in the lower half of the distribution, where higher rankings indicated greater perceived risk of occupational stress. The Greek sample was ranked first in all models, and the Irish sample ranked last in all models.

Conclusions: Since there is sociocultural variation in the perceived risk from occupational stress, it is possible that sociocultural factors influence the accuracy of national monitoring systems and the success of occupational health policy in this area.
\end{abstract}

$\mathrm{R}$ ecent government sources have labelled occupational stress a major public health and commercial issue, costing the UK economy an estimated $£ 3.7$ billion per year (1995/96). ${ }^{1}$ Trades unions make similar claims. ${ }^{2}$ Further, one estimate indicates over $60 \%$ of the British working population find their job moderately, very, or extremely stressful. ${ }^{3}$ However, there is confusion surrounding the nature and definition of stress, the evidence linking working conditions to health, and the breadth of problems attributable to occupational stress. Further, the impact of the media in portraying contemporary work as stressful is unclear. All these factors have led some to propose that occupational stress is a social construction that is not linked to poor psychological or physical health in any direct way. Such arguments have come from within the medical profession, ${ }^{4}$ social studies, ${ }^{5}$ organisational psychology, ${ }^{67}$ and policy research. ${ }^{8}$

Nevertheless, the extent to which occupational stress is a social construction might also provide a social and political imperative for public health intervention. ${ }^{9}$ That is, if members of the general public perceive occupational stress to be a salient health problem, then, in democratic societies, pressure is exerted on legislators to act on this perceived risk. Therefore, notwithstanding the scientific status of links between work, stress, and health, stress might become a public health issue if it is perceived as such in a given country.

To help answer this question, the purpose here is to examine the ranking of workers in 15 European countries with respect to the extent that work is perceived by them to influence occupational stress. If public opinion varies across European states, then it might be concluded that sociocultural factors do influence public perception of the risk from occupational stress, and in some respects, then, affected by social construction. Further, the nature of any difference in stress perceptions is informative for how both public policy should proceed, and also for understanding the extent to which minor psychiatric symptoms are attributed to work conditions in different cultural contexts.

\section{METHODS \\ Sample}

Data for this paper were taken from the Third European Survey of Working Conditions (ESWC), conducted in 2000. ${ }^{10}$ Interviewers administered the survey. INRA Europe, a market research agency, conducted the survey. Questions were standardised across countries and usually had a closed response format (for example, answers were made on rating scales), although the specific response format differed between sets of questions. Interviews were conducted in the national language for each country in participants' own homes. Participants were selected randomly through a two step procedure. First, households were selected at random within postal codes. Second, an interviewer approached each household and the person in work whose birthday was next following the interview date was requested to participate. Comparisons between the EUROSTAT Labour Force Survey and the 1995 ESWC indicate that this sampling method produces samples representative of the wider working population. $^{10}$

The sample consisted of workers or self-employed persons from 15 European countries $(n=21703$, average response rate $58.6 \%$ in each country, range $39 \%$ (Italy) to $76 \%$ (Germany)). For the purposes of cross-national comparisons, responses were included in the analyses only if individuals were working in the same country as their nationality. In this way, variation within individuals due to multiple influences of work cultures was minimised. Responses were also excluded if there were missing data on any of the variables included in the analyses.

\section{Measures \\ Perceived risk of occupational stress}

One set of questions in the survey required participants to indicate whether they believed work affected their health in a number of ways (for example, stress, hearing, stomach ache, muscular pains; responses were "yes" $=1$, "no" $=0$, or "don't know" — coded as missing). Principal components analysis of these items with the entire sample $(n=21703)$ indicated that the "stress" item loaded on the same factors as items assessing "anxiety", "irritability", "sleeping problems", "stomach ache", "headaches", and "overall fatigue" (all $r>0.40$ in the pattern matrix, no cross-loadings exceeding $|0.40|$, OBLIMIN rotation). These items are exemplary of the kinds of psychological and psychosomatic symptoms attributed to stress, ${ }^{11}$ and together, these items formed a coherent scale $(\alpha=0.73)$. Therefore the items were summed to form 


\section{Main messages}

- Sociocultural factors in Austria, Ireland, and Great Britain appear to reduce perceived risk from occupational stress among workers.

- Sociocultural factors in Greece, Italy, and France appear to increase perceived risk from occupational stress among workers.

an index of perceived risk from occupational stress $($ mean $=0.92, \mathrm{SD}=1.41$, range $0-7)$.

\section{Perceived job conditions}

Some 59 questions assessing perceptions of job conditions were subjected to principal components analysis with OBLIMIN rotation with the entire sample. The Scree plot indicated eight factors could account adequately for the data. These factors are similar to major classes of job characteristics linked to psychological wellbeing and stress. ${ }^{12}{ }^{13}$ These factors were labelled "good physical conditions", "repetitive work", "control and skill use", "managerial control", "teamwork and support", "discrimination and violence at work", "low pace of work", and "problems with customers or clients". Variables were scored using the regression procedure in the FACTOR procedure in SPSS version 10 (which produces scales with mean $=0.00, \mathrm{SD}=1.00$; these figures were approximately the same for the sub-sample used in the analyses).

\section{Job dissatisfaction}

Job dissatisfaction is a major component of work related psychological wellbeing, and often thought as a key symptom of occupational stress. ${ }^{12}$ Overall job dissatisfaction was assessed with a single item ( $1=$ "very satisfied", $4=$ "not at all satisfied", mean $=1.84, \mathrm{SD}=0.72$ ).

\section{Statistical methods}

Since individual responses were nested in industrial sectors, in turn nested in countries, three level hierarchical linear modelling was used to analyse the data using the HLM-5 program. ${ }^{14}$ Since the index of perceived risk from occupational stress was both skewed and consisted of count data (that is, the number of stress symptoms attributed to work), data were analysed using a Poisson sampling model. Three models were fitted to the data. The first model examined differences between individuals in different countries, controlling only for industrial sector. The second model examined differences between countries, controlling for industrial sector and individual level demographic variables. The third model built on the second model by additionally controlling for perceived job conditions and job dissatisfaction. This third model was thought to be the best model. By controlling for differences in demographics and psychosocial work conditions, the third model reflects best the unique effects of sociocultural influences on perceived risk from occupational stress. ${ }^{15}$

In the case of the second and third models, to ease estimation and interpretation, the regression slopes for individual level variables were fixed to be constant across each country, continuous variables were centred at the overall mean for participants included in the analysis, and dummy variables left in their natural metric. ${ }^{16}$

\section{RESULTS}

The final sub-sample, used in these analyses, consisted of 11054 responses. Some $54.4 \%$ of the sample were male and

\section{Policy implications}

- In countries where workers perceive least risk from occupational stress, such as Great Britain, monitoring systems might under-report the scale of occupational stress in the working population. The converse might be true in countries where workers perceive greatest risk from occupational stress.

- In countries where workers perceive least risk from occupational stress, actions recommended by policy makers to workers and managers are less likely to be heeded.

- Effective risk communication might reduce the impact of sociocultural factors on perceived risk from occupational stress.

the average age was 38.1 years ( $\mathrm{SD}=11.2$ ). Clerks comprised $17.4 \%$ of the sample, service and sales workers $16.3 \%$, technicians and other associate professionals $15.3 \%$, craft workers $14.9 \%$, professionals $12.3 \%$, plant and machine operators $9.0 \%$, elementary occupations $8.4 \%$ (for example, domestic help, refuse collection), senior officials and senior managers $4.8 \%$, skilled agricultural and fisheries workers $1.1 \%$, and armed forces personnel $0.6 \%$. Some $87 \%$ of the sample had a permanent contract and $19.5 \%$ worked shifts. The modal value for hours worked per week was 30 and 39 hours per week (range $<10$ hours to $60-80$ hours). The modal value for tenure with the organisation was 10-14 years and the modal value for tenure in current job was 2-3 years (range $<1$ year to $\geqslant 35$ years for both). Workers were from the public sector $(30.3 \%)$, manufacturing $(20.7 \%)$, retail and wholesale trade $(16.1 \%)$, services $(15.9 \%)$, construction $(7 \%)$, transport $(5 \%)$, post and telecommunications $(2.5 \%)$, agriculture and fisheries (1.6\%), and public utilities (1.0\%). Table 1 shows the number of responses from each country.

In each of the three models estimated, there was significant variation between countries on the index of perceived risk from occupational stress $\left(\chi^{2}=269.68\right.$ for first model; $\chi^{2}=334.09$ for second model; $\chi^{2}=389.75$ for third model; $\mathrm{df}=14, \mathrm{p}<0.001$ for all models). These results indicate that controlling for demographics, perceived job conditions, and job dissatisfaction does not explain all of the variation between countries in perceived risk of occupational stress. Table 1 shows the estimated the number of stress symptoms for each regression model between countries, and the rank of each country on these estimates. The results show that workers in Austria and Ireland are least likely to believe work causes stress symptoms, even after controls for demographics, perceived work conditions, and job satisfaction. Workers in Greece are among those most likely to believe work causes stress symptoms. The results indicate, in general, that British workers are less likely than workers in many other western European nations to believe work causes stress symptoms. Further, the rank of the British sample drops by three positions to 13th after controls for sector, demographics, job dissatisfaction, and perceived work conditions. This indicates that sociocultural factors in Britain may act to suppress perceived risk from occupational stress, even if demographic factors, psychosocial work characteristics, and job dissatisfaction act to increase perceived risk.

\section{DISCUSSION}

The results indicate that sociocultural factors influence the perceived risk from occupational stress. Therefore, the results indicate occupational stress is, at least to some degree, socially constructed. 
Table 1 Estimated number* of stress symptoms attributed to work for each country from multi-level Poisson regressions

\begin{tabular}{|c|c|c|c|c|c|c|c|}
\hline & \multirow[b]{2}{*}{ Sample size $†$} & \multicolumn{2}{|c|}{ Model 1} & \multicolumn{2}{|c|}{ Model 2} & \multicolumn{2}{|c|}{ Model 3} \\
\hline & & Value & Rank & Value & Rank & Value & Rank \\
\hline Greece & 403 (27) & 1.75 & 1 & 1.51 & 1 & 1.67 & 1 \\
\hline Italy & $664(44)$ & 1.01 & 7 & 0.86 & 8 & 1.06 & 2 \\
\hline France & $868(58)$ & 1.26 & 2 & 1.15 & 2 & 1.02 & 3 \\
\hline Luxembourg & 211 (42) & 1.08 & 4 & 0.87 & 7 & 1.01 & 4 \\
\hline Spain & 698 (47) & 1.04 & 6 & 0.90 & 4 & 1.00 & 5 \\
\hline Belgium & $844(55)$ & 0.96 & 8 & 0.89 & 6 & 1.00 & 6 \\
\hline Sweden & $939(60)$ & 1.14 & 3 & 0.96 & 3 & 0.55 & 7 \\
\hline Finland & 742 (50) & 1.06 & 5 & 0.90 & 5 & 0.91 & 8 \\
\hline Portugal & 775 (52) & 0.68 & 11 & 0.57 & 13 & 0.78 & 9 \\
\hline Denmark & $826(55)$ & 0.66 & 13 & 0.61 & 12 & 0.76 & 10 \\
\hline Netherlands & 996 (66) & 0.72 & 10 & 0.70 & 9 & 0.70 & 11 \\
\hline Germany & $743(48)$ & 0.67 & 12 & 0.61 & 11 & 0.70 & 12 \\
\hline Great Britain & 876 (58) & 0.74 & 9 & 0.66 & 10 & 0.62 & 13 \\
\hline Austria & $652(43)$ & 0.46 & 14 & 0.40 & 14 & 0.48 & 14 \\
\hline Ireland $\ddagger$ & 817 (54) & 0.30 & 15 & 0.25 & 15 & 0.31 & 15 \\
\hline \multicolumn{8}{|c|}{$\begin{array}{l}\text { *Estimates calculated from natural log of intercept for Poisson regressions. } \\
\text { tFigures in parentheses represent sample size expressed as a percentage of the entire sample size for each } \\
\text { country. } \\
\text { flncludes Northern Ireland. }\end{array}$} \\
\hline
\end{tabular}

\section{Limitations of the study and unanswered questions for future research}

The inclusion criteria for the analyses reported in this study meant that many participants' data were excluded from the analyses. For many countries, around 50\% of participants' data were excluded, because either they did not work in the same country as their nationality or had provided some missing data. For the Greek sample however, over $70 \%$ of the entire sample were excluded from the analyses. Nevertheless, controlling for extraneous factors in statistical models 2 and 3 mitigates against potential selection bias to some degree.

The reasons for the relative standing of different countries have not been investigated in this paper. Two potential candidates are sociocultural factors related to health perceptions, and the role of the media in portraying various health risks. ${ }^{17}{ }^{18}$ For example, the individualist orientation of British society is associated with risk tolerance, ${ }^{18}$ which might go some way to explaining why members of the British sample are less likely to perceive that work causes stress symptoms. ${ }^{19}$ However, it is not certain that similar sociocultural factors are present in Ireland or Austria, or absent in France and Greece, for example.

\section{Implications for policy and practice}

The results indicate that those presenting to health practitioners with symptoms of minor psychiatric disorder or nonspecific psychosomatic symptoms in Great Britain (and other similarly ranked countries on the analyses reported here) may be less likely to attribute those symptoms to work than in many other higher ranked European countries. It might be that those presenting with such symptoms might attribute them erroneously to other life domains. For health practitioners, this might lead to misdiagnosis and poor treatment of individuals' underlying problems. This might also lead to under-reporting of the problem of occupational stress through national monitoring systems based on health practitioner report. ${ }^{20}$ Subsequently, health policy makers might underestimate any problems of occupational stress, and place a lower priority on occupational stress and/or assume existing policy contains effectively any problems. In countries where there is greater average perceived risk of occupational stress, symptoms might be overly and erroneously attributed to the work domain, possibly leading to misdiagnosis, over-estimation of any problems through national reporting systems, and consequently ill informed policy decisions.

These data cannot shed light on the extent to which the prevalence of psychosocial harm attributable to work warrants sustained government and/or organisational action. However, the results reported here do indicate that relative to many other European countries, policy makers in Great Britain have yet to make a convincing case to the general British working population for such action. As such, any recommended actions made to workers or managers are less likely to be heeded in Britain and other similar ranked countries, ${ }^{19}$ especially if inspection is lax or difficult to achieve, or if action is made in the form of advice-and therefore open to greater interpretation and volition-rather than being legally binding. ${ }^{21}$ This would indicate that public policy should concentrate on effective communication of the real risks of occupational stress, so that workers and managers have a more objective, evidence based view of occupational stress that is less contaminated by sociocultural factors. Similar conclusions could be drawn for those countries with a similar ranking to Britain.

Two caveats should be noted here though. First, effective risk communication entails making open and public areas of scientific doubt and uncertainty: ${ }^{19}$ limitations on the evidence base and areas of genuine scientific doubt need to be made clearer to the public. Without so doing, the media and other vested interests will be able to use divided scientific opinion to promote their own case and leaving the public, most likely, to side with stakeholders that promote a view which best fits their own opinion. ${ }^{22}$ The results here indicate that for many in the British population, this would mean a continued lower perception of risk than in many other European countries.

Second, care must be taken to ensure that risk messages do not cause undue alarm. Since the symptoms of occupational stress tend to be non-specific, ${ }^{23}$ a potential danger is that this may lead to greater absence and presentation to health professionals among the "worried-well", as individuals observe consonance between what they perceive as their own symptoms and the symptoms of chronic occupational stress. In turn, this might lead to an overestimation of problems attributable to stress through national reporting schemes, with subsequent problems for deciding on appropriate policies. ${ }^{20}$ While this is unlikely to be a general problem in the British population and other similarly ranked countries at the moment, it could already be a problem in European 
countries where the average perception of risk from occupational stress is much higher. In these latter countries, effective risk communication could focus on the real risks of occupational stress, but with a view to reducing public perception of risk.

\section{Conclusion}

Sociocultural factors may influence the perceived risk from occupational stress. Therefore, it is possible that these sociocultural factors influence the extent to which monitoring systems are able to detect accurately psychosocial harm resulting from work as well as the extent to which workers and managers act on advice from policy makers. Effective risk communication may act to minimise the influence of sociocultural factors, but inappropriate risk communication might accentuate any problems.

\section{ACKNOWLEDGEMENTS}

I am grateful to the European Foundation for the Improvement of Living and Working Conditions for making available data from the 3rd European Survey of Working Conditions.

Correspondence to: Prof. K Daniels, Business School, Loughborough University, Leicestershire LE1 1 3TU, UK; k.j.daniels@lboro.ac.uk

Accepted 28 November 2003

\section{REFERENCES}

1 www.hse.gov.uk/stress/index.htm. 4 November 2003.

2 www.tuc.org.uk/h_and_s/tuc-5657-f0.cfm. 4 November 2003.

3 Smith $\mathrm{A}$, Johal $\mathrm{S}$, Wadsworth $\mathrm{E}$, et al. The scale of occupational stress: the Bristol stress and health at work study. Sudbury: HSE Books, 2000.

4 Wesseley S, Hotopf M. Are some public health issues better neglected? Lancet 2001;357:976-7.
5 Pollock K. On the nature of social stress: production of a modern mythology. Soc Sci Med 1988;26:381-92.

6 Briner RB, Reynolds S. Bad theory and bad practice in occupational stress. Occupational Psychologist 1993;19:8-13.

7 Newton T. "Managing stress" emotion and power at work. London: Sage, 1995.

8 Rick J, Hillage J, Honey S, et al. Stress: big issue, but what are the problems? Brighton: The Institute for Employment Studies, 1997.

9 Hood CC, Jones DKC, Pidgeon NF, et al. Risk management. In: Risk: analysis, perception and management. London: Royal Society, 1992.

10 Paoli P, Merllie D. Third European survey of working conditions. Dublin: European Foundation for the Improvement of Living and Working Conditions, 2001.

11 Daniels K. Stressed? In: Billsberry J, ed. The effective manager: perspectives and illustrations. London: Sage, 1996.

12 Cooper C. Job distress and the emerging role of the clinical occupational psychologist. Bull Br Psychol Soc 1986;39:325-31.

13 Warr PB. Work, unemployment and mental health. Oxford: Oxford University Press, 1987.

14 Bryk AS, Raudenbush SW, Cheong YF, et al. HLM5: hierarchical linear and nonlinear modelling. Chicago: Scientific Software International, 2000.

15 Snijders T, Bosker R. Multilevel analysis: an introduction to basic and advanced multilevel modeling. London: Sage, 1999.

16 Bryk AS, Raudenbush SW. Hierarchical linear models. Newbury Park, CA: Sage, 1992.

17 Kasperson RE, Kasperson JX, Renn O. The social amplification of risk: progress in developing an integrative framework. In: Krimsky S, Golding D, eds. Social theories of risk. London: Praeger, 1992.

18 Thompson M, Ellis R, Wildavsky A. Cultural theory. Boulder, CO: Westview, 1990.

19 Daniels K. Why aren't managers concerned about occupational stress? Work \& Stress 1996;4:352-66.

20 Daniels K, Jones D, Perryman S, et al. Cognitive and perceptual factors' influence on the expression and reporting of work-related stress. Sudbury: HSE Books, in press.

21 Scott WR. Institutions and organizations. Thousand Oaks, CA: Sage, 1995.

22 Handmer J, Penning-Rowsell E. Hazards and the communication of risk. Aldershot: Gower, 1990.

23 Spurgeon A, Gompertz D, Harrington JM. Non-specific symptoms in response to hazard exposure in the workplace. J Psychosomatic Res 1997;43:43-9 